\title{
DETERMINATION OF USE OF DENTAL MATERIALS AND STOMATOLOGICAL FREES ON STAND
}

\author{
Alexandru Saracin ${ }^{1}$, Gheorghe Voicu ${ }^{1}$, Ion Saracin ${ }^{2}$, Pandia Olimpia ${ }^{3}$ \\ ${ }^{1}$ University Politehnica of Bucharest, Romania; ${ }^{2}$ University of Craiova, Romania; \\ ${ }^{3}$ University of Agronomic Sciences and Veterinary Medicine of Bucharest, Romania \\ saracin.alex@gmail.com,ghvoicu_2005@yahoo.com, ion_saracin@yahoo.com, \\ olimpia_pandia@yahoo.com
}

\begin{abstract}
The authors propose in this paper testing of materials used in dental constructions and dental cutters used for their processing on an electric stand, made by the authors. The stand will be equipped with a transmission that ensures variation of the rotation speed of the cutter from 3000 to $30000 \mathrm{rpm}$, variation of the sample rotation speed of the tested material from 10 to $300 \mathrm{rpm}$, vertical and horizontal plane and horizontal rotation mechanisms. The operation of the stand is considered to be simple. In order to carry out the tests, it is necessary and obligatory that the sample preparation operation is carried out in accordance with the validation standards, namely, the knowledge of the sample material, the mechanical properties, the dimensions and their weight. After mounting the samples and the cutter on the stand, the pressing force is established by adding additional weights, the rotation speed of the sample is set and the rotation speed of the cutter is also set to the horizontal movement speed to the cutter (measured in microns) by means of a micrometric screw mounted on the table stand acting on the sample holder.It measures the test time, determines the shape, dimensions and the weight of the samples after each period of time. Following the determinations we can observe the proportionality of the friction force with normal reaction, the connection between the coefficient of friction and the rotation speed during the test, the quality of the sample surfaces and the milling cutter subjected to the test.The study was conducted to determine the wear properties of dental cutters used in dental laboratories, where many materials with different mechanical and technological properties are used.
\end{abstract}

Keywords: dental cutter, sample, stand, wear,cutting surface.

\section{Introduction}

All dental instruments are manufactured according to EN ISO-Standard 6360. In order to achieve compliance, the International Organization for Standardization (ISO) has defined a standard description of rotary tools used in dental technology. The following are most relevant: each tool is encoded with a distinct ISO code. This code consists of 15 numbers that are arranged in groups and simultaneously contain the description of the instrument [1] (Fig. 1).

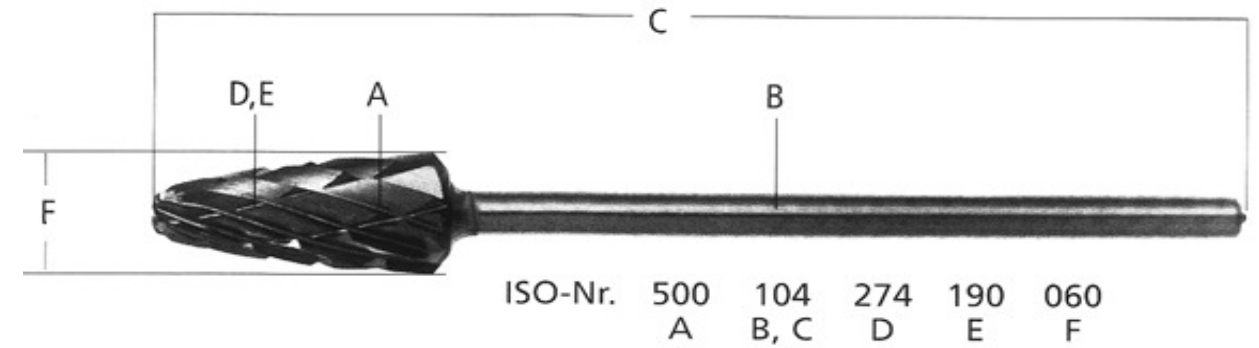

Fig.1. Standard description of rotary instruments used in dental techniques: A - workpiece material 500 - for carbides; B,C - measure and total length 104 - for the right hand piece; D - cutting surface and granule size 274 - for the shape of the workpiece; E - dimension to cutting 190 - for teeth the largest diameter of the work piece at $0.1 \mathrm{~mm} ; \mathrm{F}$ - diameter at the base of the cutting edge

Types of mills used for testing (Fig. 2)

$\mathrm{X}$-Mas Tree cutter, diamond for the turbine, of different sizes and hardnesses. Made by the special HBN technique by Strauss \& Co, it provides a homogeneous diamond surface. The diamond particle mixture, specially produced by Strauss \& Co, offers the best results in cavity preparation [2].

Head size: $038 \mathrm{~mm}$

Total milling length: $21 \mathrm{~mm}$.

Head length: $7 \mathrm{~mm}$.

Hardness: Green ring - hard 


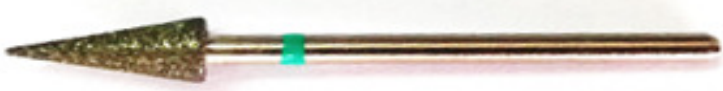

Fig.2. X-Mass Tree diamond cutter

Diamond rounded cutter with PR1 rounded tip, overview (Figure 3), dDiamantine, cylindrical rounded tip turbine, of various sizes and hardness. Made by the special HBN technique by Strauss \& Co, it provides a homogeneous diamond surface. The diamond particle mixture, specially produced by Strauss \& Co., offers the best results in cavity preparation [2].

Head size: $0.12 \mathrm{~mm}$

Overall milling length: $23.5 \mathrm{~mm}$.

Head length: $10 \mathrm{~mm}$.

Hardness: no marking, medium.

Green ring: harsh

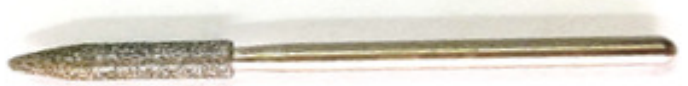

Fig.3. Round cylindrical cutter with rounded tip PR1

\section{Materials and methods}

Research on macro-microscopic analysis and hardness for mills used in stomatology

The preparation of samples for macro-microscopic analysis is carried out according to the following reference standards [3]:

- STAS 4203-74 "Metallography. Taking and preparing metallographic samples",

- STAS 5500-74 "Metallography. Defects. Terminology".

According to STAS 4203-74, the preparation of metallographic samples for microscopic analysis consists of 4 stages:

- sampling,

- polishing the samples,

- polishing the samples,

- metallographic attack.

All these images were captured using an OLYMPUS metallographic microscope equipped with a camera and STREAM ESSENTIALS imaging software [4].

Given the fact that the nature of the material was not known, $2 \%$ Nital attack was used. The microstructures of Fig. 4 were obtained - sample 1 and Fig. 5 - sample 2 (magnification power 500x).

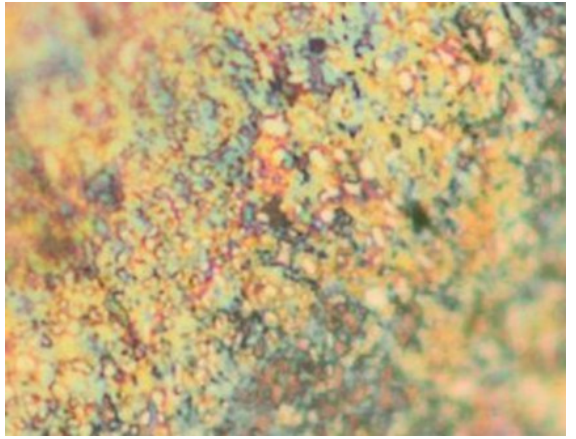

Fig. 4. Sample microstructure 1 (500X)

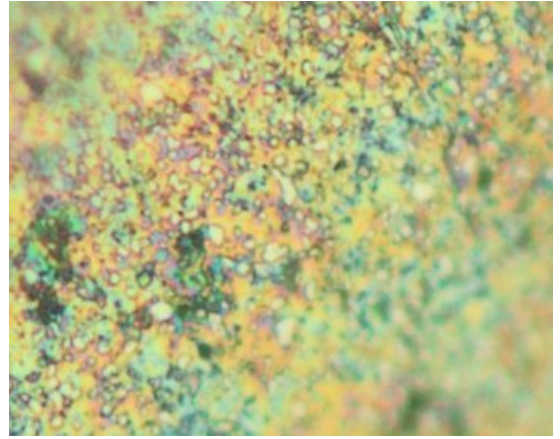

Fig. 5. Sample microstructure 2 (500X) 


\section{Study of fretting hardness}

The test consists in slow application with a known load in a limited time (10-15 $\mathrm{s}$ in the case of steels) of a straight pyramidal penetrator with a square base and the dihedral angle at the top of the opposing faces of $136^{\circ}$ placed on the surface of the sample [5;6].

For the microstructure test the test forces are between $0.98 \mathrm{~N}$ and $49 \mathrm{~N}$, corresponding to hardnesses HV 0.1 and less than HV 5, and for the macro durability test the test forces are between $49 \mathrm{~N}$ and $980 \mathrm{~N}$, corresponding to hardness HV 5 and HV $100[7 ; 8]$.

We will use an Innovatest Vickers micronutrient.

For this paper it is of interest and will be retained the breaking strength, in $\mathrm{MPa}$, at compressive stress. At least 3 measurements of each sample in the core and edge (i.e., close to the cutting edge of the cutter) will be made. The values in Table 1 were obtained. The pushing force is $0.5 \mathrm{kgf}$ and the penetrator holding time is 10 seconds [9].

\section{Breaking strength, in MPa, at compressive load}

\begin{tabular}{|c|c|c|c|}
\hline Sample number & Location & HV & $R_{m}, \mathbf{M P a}$ \\
\hline \multirow{6}{*}{1} & \multirow{3}{*}{ Middle } & 292.3 & 939.2 \\
\hline & & 293.4 & 943.4 \\
\hline & & 290.2 & 930.5 \\
\hline & \multirow{3}{*}{ Margin } & 378.8 & 1216.4 \\
\hline & & 370.5 & 1191.6 \\
\hline & & 378.4 & 1215.2 \\
\hline \multirow{6}{*}{2} & \multirow{3}{*}{ Middle } & 286.5 & 919.5 \\
\hline & & 289.9 & 929.7 \\
\hline & & 294.2 & 946.7 \\
\hline & \multirow{3}{*}{ Margin } & 287.1 & 921.4 \\
\hline & & 288.7 & 926.1 \\
\hline & & 289.6 & 928.9 \\
\hline
\end{tabular}

\section{Presentation of the test bench}

The authors propose in this paper a test stand, having the composition shown in Figure 6.

After conducting the test samples according to the validation standards, measurements shall be made weighing both the test material and the test cutters.

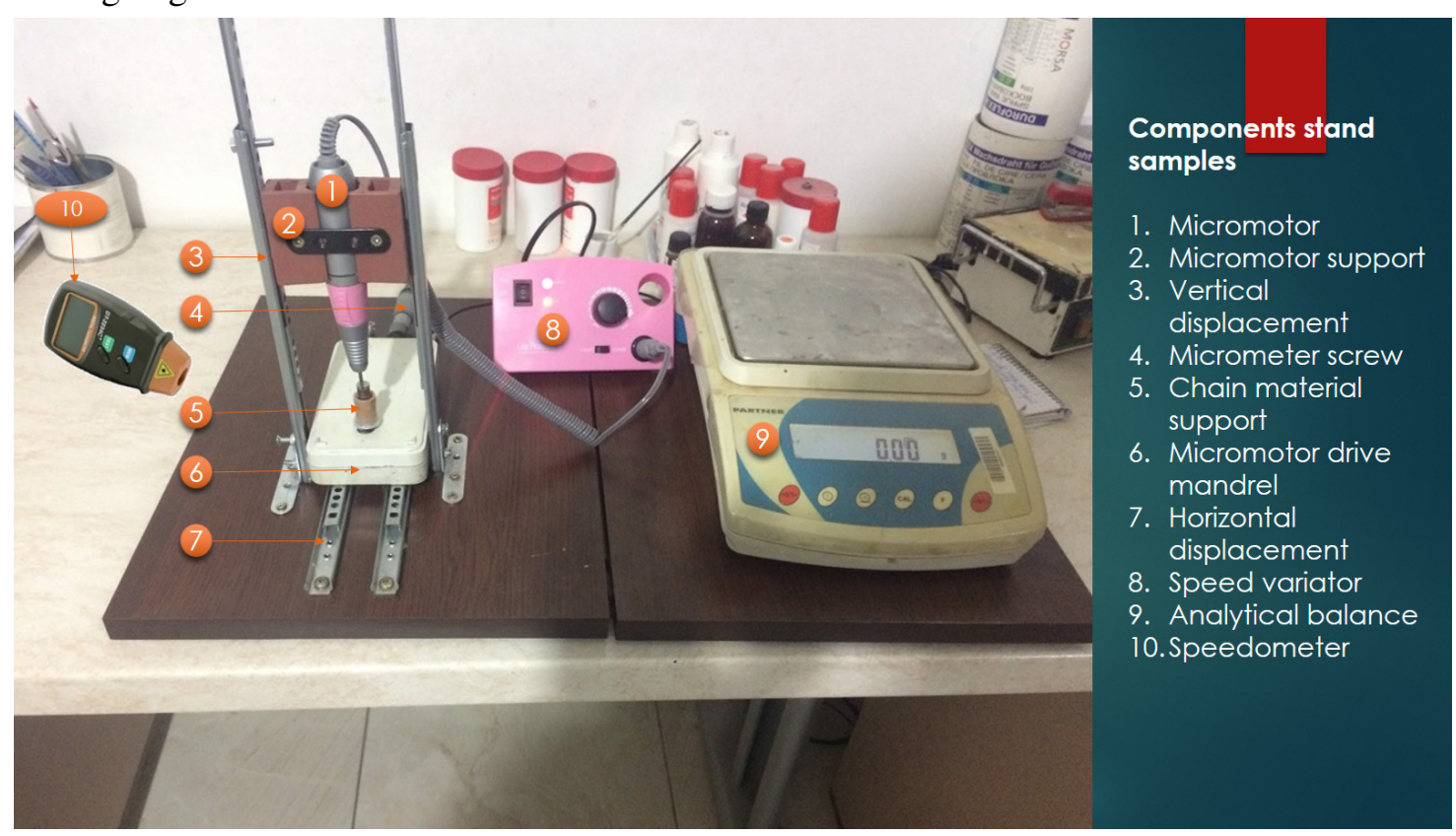

Fig. 6. Stand dental milling tests [10] 
The measured and weighed samples are mounted on the support table, where the clamping clamps are provided to provide rotational movement. Afterwards, the cutting force on the samples is adjusted and the corresponding notches are placed on the handles.

Afterwards, the test time is determined, thus determining the speed at which the milling will be performed. The next step is to determine the rotation speed and sample rate and the movement of the sample table.

At the end of the test time dimensional measurements shall be made and both the samples and the mills used for the test shall be weighed. Samples will be collected and their size determined, this being influenced by the rotation speed of the cutter and the velocity of the table moving with the samples [10].

\section{Results and discussion}

The experimental results will be noted in a table, as shown in Table 2.

Table 2

Experimental results

\begin{tabular}{|c|c|c|c|c|c|c|c|c|c|}
\hline $\begin{array}{l}\text { No. } \\
\text { of } \\
\text { test }\end{array}$ & $\begin{array}{c}\text { Type of } \\
\text { cutter }\end{array}$ & $\begin{array}{l}\text { Sample } \\
\text { material }\end{array}$ & $\begin{array}{c}\text { Test } \\
\text { time, } \\
\text { min }\end{array}$ & $\begin{array}{l}\text { Rotation } \\
\text { speed, } \\
\text { rpm }\end{array}$ & $\begin{array}{c}\text { Sample } \\
\text { speed, } \\
\text { rpm }\end{array}$ & 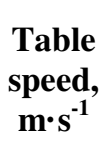 & $\begin{array}{c}\text { Force } \\
\text { pressure, } \\
\mathbf{N}\end{array}$ & $\begin{array}{c}\text { Chip } \\
\text { thickness, } \\
\mu \mathrm{m}\end{array}$ & $\begin{array}{c}\text { Milling } \\
\text { table, } \\
\text { g }\end{array}$ \\
\hline \multirow{4}{*}{1} & \multirow{4}{*}{$\mathrm{F}_{1}$} & \multirow{4}{*}{ M1 } & 5 & 7000 & 100 & 0.1 & 2 & 0.1 & 1.76 \\
\hline & & & $5-10$ & 10000 & 100 & 0.1 & 3 & 0.1 & 1.74 \\
\hline & & & $10-15$ & 20000 & 100 & 0.1 & 4 & 0.1 & 1.73 \\
\hline & & & $15-20$ & 30000 & 100 & 0.1 & 4 & 0.1 & 1.71 \\
\hline \multirow{4}{*}{2} & \multirow{4}{*}{$\mathrm{F}_{2}$} & \multirow{4}{*}{ M1 } & 5 & 7000 & 100 & 0.1 & 2 & 0.1 & 1.78 \\
\hline & & & $5-10$ & 10000 & 100 & 0.1 & 3 & 0.1 & 1.76 \\
\hline & & & $10-15$ & 20000 & 100 & 0.1 & 4 & 0.1 & 1.74 \\
\hline & & & $15-20$ & 30000 & 100 & 0.1 & 4 & 0.1 & 1.71 \\
\hline
\end{tabular}

Based on the results in the table above, the degree of mechanical wear of the samples and frets during the test will be determined, taking into account the rotational speed, the translation speed and the pressing force [10].

For F1 and M1 it was found that the greatest impact on wear was due to the speed rather than the compression force

Starting at a speed of $20000 \mathrm{rpm}$ up to $30000 \mathrm{rpm}$ at the same pressing force, wear decreases significantly by $0.02 \mathrm{~g}$

For F2 and the M1 sample of the same material the same speed and press force were found to have a significant wear of $0.03 \mathrm{~g}$, which leads to the conclusion that wear depends on the properties of the dental cutter.

\section{Conclusions}

1. For the microstructure test the test forces are between $0.98 \mathrm{~N}$ and $49 \mathrm{~N}$, corresponding to hardnesses HV 0.1 and less than HV 5

2. For the macro durability test the test forces are between $49 \mathrm{~N}$ and $980 \mathrm{~N}$, corresponding to hardness HV 5 and HV 100.

3. The samples have the same core hardness (middle area).

4. The samples have elevated hardness (over $280 \mathrm{HV}$ ).

5. The samples exhibit very high resistance to compressive stress (over $900 \mathrm{MPa}$ ).

6. An increase in hardness for sample 4 to the edge is observed by $28.7 \%$, unlike sample 3 having the same characteristics (hardness and compressive strength) regardless of the hardness measuring position.

7. A fine and similar granular structure was noted for the two cutters, the fine grain structure noted at the microscope is mainly due to nickel. 


\section{References}

[1] Patrascu I. Dental materials (Materiale dentare), Ed. Horanda press, Buc., 2002 (In Romanian).

[2] Sărăcin I. A. Elaboration of experimentation methodology and necessary equipment (Elaborarea metodologiei de experimentareși aparatura necesară), UPB, 2019 (In Romanian).

[3] Pascu D., R., s.a., Structural amd mechanical characterization of S355J2 weldeable steel from the plan safety gate construction - PdF1 DrTrSeverin, The 6th International Conference - Innovative technologies for joining advanced materials, 2012, pp. 86-93.

[4] Croitoru Gh., Rusu I., Carbon nanotube/cement composites (Componente de nanotuburi de carbon /ciment), International Scientific Conference ULGALMAT, 2009.

[5] Antoniac I.V. "Handbook of Bioceramics and Biocomposites" , Ed.Springer International Publishing Switzerland,2016, vol.I.

[6] Tărâţă D., F., Ivănuş R., Study materials. Guidance for laboratory work (Studiulmaterialelor. Îndrumătorpentrulucrări de laborator), EdituraUniversitaria, Craiova, 2007 (In Romanian).

[7] Mirițoiu C., M., Pădeanu A., Metal constructions. Laboratory Guidance(Construcţiimetalice. Îndrumar delaborator), Ed. SITECH, Craiova, 2016 (In Romanian).

[8] Sărăcin I., Mechanics and strength of materials (Mecanica șirezistenț a materialelor), Ed. AIUS, Craiova, 2007 (In Romanian).

[9] Adrian J.C. Tissue response to base metal dental alloys. Military Med. 1977, pp.742-784.

[10] Voicu G. Simulation of mechanical behaviour in milling and polishing of dental polymeric (resin) composites, Rev. MasePlastice, 2018. 